\title{
A Review of Adult Obesity Prevalence, Trends, Risk Factors, and Epidemiologic Methods in Kuwait
}

\author{
Stalo Karageorgi, ${ }^{1}$ Osama Alsmadi, ${ }^{1}$ and Kazem Behbehani ${ }^{2}$ \\ ${ }^{1}$ Genome Centre, Dasman Diabetes Institute, P.O. Box 1180, Dasman, 15462 Kuwait City, Kuwait \\ ${ }^{2}$ Dasman Diabetes Institute, P.O. Box 1180, Dasman 15462, Kuwait \\ Correspondence should be addressed to Stalo Karageorgi; stalo.karageorgi@dasmaninstitute.org
}

Received 1 August 2013; Accepted 17 October 2013

Academic Editor: Renato Pasquali

Copyright (c) 2013 Stalo Karageorgi et al. This is an open access article distributed under the Creative Commons Attribution License, which permits unrestricted use, distribution, and reproduction in any medium, provided the original work is properly cited.

\begin{abstract}
Objective. Kuwait is among the countries with the highest obesity rates worldwide; however, little is known about the state of obesity epidemiology research in Kuwait. In this paper, we therefore review the findings and methodology of studies on the prevalence, trends and risk factors of obesity in Kuwait. Methods. The PubMed database was searched using the keyword combination: obesity and adults and Kuwait. Out of 111 articles, 39 remained after abstract review, and 18 were selected after full-text review. Results. The studies were all cross-sectional and published in the last fifteen years (1997-2012). The sample size ranged from 177 to 38,611 individuals. Only $30 \%$ of studies used random sampling. The prevalence (BMI $\geq 30$ ) in studies with a nationally representative sample ranged from $24 \%$ to $48 \%$ overall and in adults $>50$ years was greater than $52 \%$. Rates were significantly higher in women than those in men. Studies that examined trends showed an increase in obesity prevalence between 1980 and 2009. Multiple risk factors including sociocultural factors were investigated in the studies; however, factors were only crudely assessed. Conclusion. There is a need for future studies, particularly surveillance surveys and prospective cohort studies utilizing advanced methods, to monitor trends and to comprehensively assess the factors contributing to the obesity epidemic in Kuwait.
\end{abstract}

\section{Introduction}

Obesity prevalence rates have increased worldwide in the last three decades from 1980 to 2008 , reaching a prevalence of $10-14 \%$ among the world's adult population in 2008 [1]. Even though obesity rates are higher in upper-middle income and high income countries [2], they are projected to increase rapidly in developing nations [3]. Body mass index (BMI) is the most common way of assessing obesity and is a measure of weight that adjusts for height [4] and correlates highly with body fatness [5]. Waist circumference (WC) on the other hand is a surrogate measure for abdominal fat and is suggested to be a better predictor for certain chronic diseases [4]. Obesity has been linked to a multitude of health conditions including diabetes, hypertension, ischaemic stroke and heart disease, different types of cancers, osteoarthritis, and reproductive conditions [4]. As a result, obesity is now among the leading factors for global morbidity and mortality and causes more global deaths than underweight [6].

Economic growth, urbanization, and subsequent changes in lifestyle are among the factors driving the global obesity epidemic [7]. The rapid speed that the above factors advanced in countries of the Gulf region since the discovery of oil in the late 1930s may have exacerbated the obesity epidemic in these countries including Kuwait [8]. The state of Kuwait ranks in the top $7 \%$ of countries worldwide with the highest adult obesity prevalence rates according to the International Comparisons data from the WHO Global Infobase [9] and is in the top 3\% of countries worldwide with the highest diabetes prevalence rates according to recent data from the International Diabetes Federation [10]. Kuwait, a high income economy, borders Iraq and Saudi Arabia, has a total population of 3,784,263, and is divided in six governorates (Figure 1). Only $32 \%$ of the total population are Kuwaitis with 


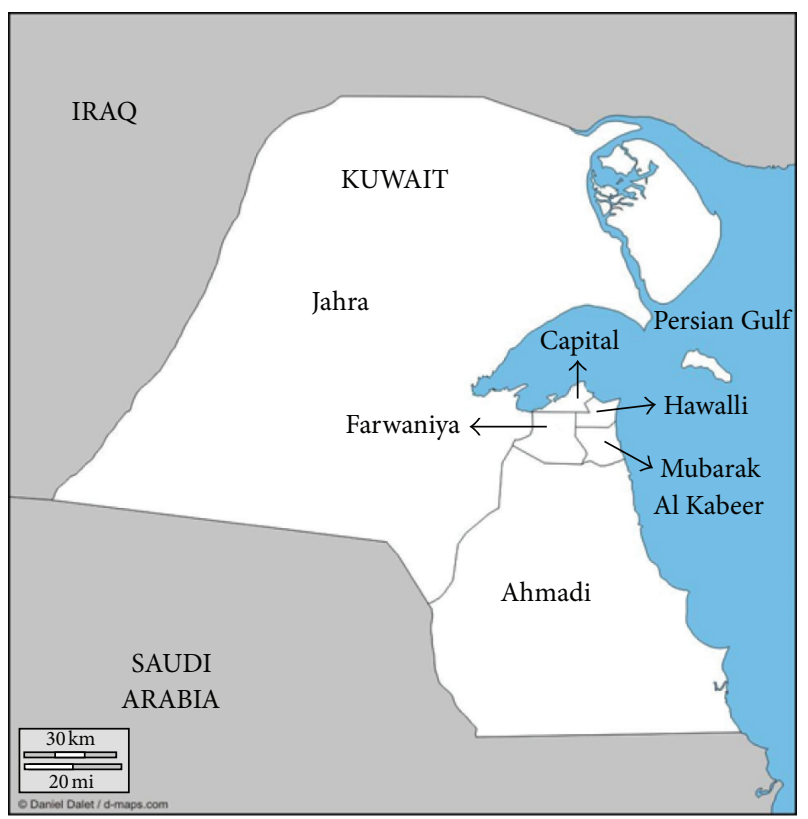

Figure 1: Map of the six governorates in Kuwait. Population by governorate in year 2012: Farwaniya $(999,858)$, Hawalli $(822,678)$, Ahmadi (738,023), Capital $(514,198)$, Jahra $(474,751)$, and Mubarak Al Kabeer $(229,210)$. Population size represents both Kuwaiti and non-Kuwaiti nationals [11].

the remaining being Arabian (28\%), Asian (38\%), and other ethnicities (3\%) [11].

The alarming levels of obesity and deleterious health consequences on the population of Kuwait led us to conduct a scientific review to evaluate the current state of obesity epidemiology research in Kuwait. Previous studies have reviewed obesity prevalence rates and causes in Arabic speaking countries [12], the Middle East [13], the Eastern Mediterranean $[14,15]$, and the Gulf region [16, 17]; however, none have focused exclusively on Kuwait. In this paper, we therefore summarize, classify, and synthesize available information on this subject. The purpose of this review is to conduct an exhaustive search and inclusion of obesity epidemiology studies in Kuwait in order to assess both research methodology and research findings. Studies are drawn from the literature reporting on the prevalence, trends, and risk factors associated with obesity in Kuwait.

\section{Methods}

The PubMed database was searched for articles using the keyword combination: obesity AND adults AND Kuwait. Obesity was defined as BMI $\geq 30$. Our search was not limited to year of publication and was limited to articles in English language. Publications were selected initially based on title and abstract review to include studies on the epidemiology of obesity and exclude studies not directly related to this subject. For the selected publications, we then conducted a full-text review and excluded studies with selfreported instead of measured weight and height, studies with redundant/overlapping data, and review studies that did not contribute new information through a meta-analysis. Among studies with data overlap, we used the study reporting the most detailed results, and for the review studies identified during the primary search, we screened their reference list for additional articles.

For each study, we retrieved information from the four study domains listed in Table 1. Finally, the reference list of retrieved articles and other science literature or public databases were searched for additional articles. Additional articles were also identified through personal communication. The last literature search was conducted on the 10th of February, 2013.

\section{Results}

The flow chart for article identification and selection is demonstrated in Figure 2. One hundred and four articles were identified in PubMed, and 32 articles [16, 17, 19-24, $26,28,30-51]$ remained after exclusion of nonepidemiologic studies based on title and abstract review. One additional article [52] was identified through personal communication and 5 articles [18, 25, 27, 29, 53] and one survey report [54] through other database searches leading to a total of 39 articles. Of the 39 epidemiology articles identified, 4 articles $[40,48-50]$ could not be retrieved and a total of 17 were excluded after full-text review for the following reasons. The excluded articles included two review studies [16, 17], one letter to editor [39], one study with self-reported BMI [36], one study that reported body weight but not height [51], one study that focused on anthropometric measures other than BMI [41], and eleven studies [37, 38, 42-47, 52-54] because of data overlap or redundancy. From among all studies with data overlap or redundancy, we selected the study reporting the most detailed results $[19,20,22-24,33,35]$. The selection process resulted in a final total number of 18 articles remaining for a thorough review [18-35] (Figure 2).

The data and information retrieved from the 18 reviewed studies are outlined in Table 2. These studies were published in the last fifteen years starting from 1997 through 2012. The data for the majority of the studies were collected in the 1993 through 2010 with the exception of one study [35] that additionally used data from the 1980s; however, there were four studies $[21,27,28,30]$ that did not report year of data collection. In studies reviewed, there was a lag of $2-5$ years for publication since the last data collection. The time it took to recruit participants in most studies ranged from one day to three years and eight months although one survey study, called the Kuwait National Nutrition Surveillance System (KNNS) survey, ran for ten years and collected data biennially [22]. Five studies did not report the recruitment time period $[20,24,27,28,30]$.

All eighteen studies reviewed used a cross-sectional study design. Five studies were national surveys (National Nutrition Survey (NNS) [19], Kuwait National Nutrition Surveillance System (KNNS) survey [22], WHO STEPS Survey [24], National Screening for Rheumatic Disorders Survey [32], and Nutrition Status Assessment of Adults Survey [35]), two 
TABLE 1: Information extracted from each reviewed study by study domain.

\begin{tabular}{llll}
\hline Study publication & Study design & Study analysis & Study results \\
\hline First author & Year of survey & Statistical methods & Sample size (percent males) \\
Publication year & Recruitment period & Statistical model adjustment factors & Age range and/or mean age \\
Author affiliation* & Study design type & Statistical software & Ethnicity or nationality \\
Journal name* & Eligibility criteria & & Obesity prevalence and/or mean BMI \\
Journal impact & Sampling source/frame & & Obesity correlates and/or trend \\
factor & Sampling method & & \\
& Response rate & & \\
& Data collection method & & \\
& Type of collected data & & \\
& Obesity category & & \\
& List of all collected variables reported* & & \\
& Other anthropometric measures* & & \\
\end{tabular}

${ }^{*}$ Data for these variables are listed in the supplementary table.

\# Obesity category refers to whether obesity was examined as the main outcome or as a risk factor for other outcomes.

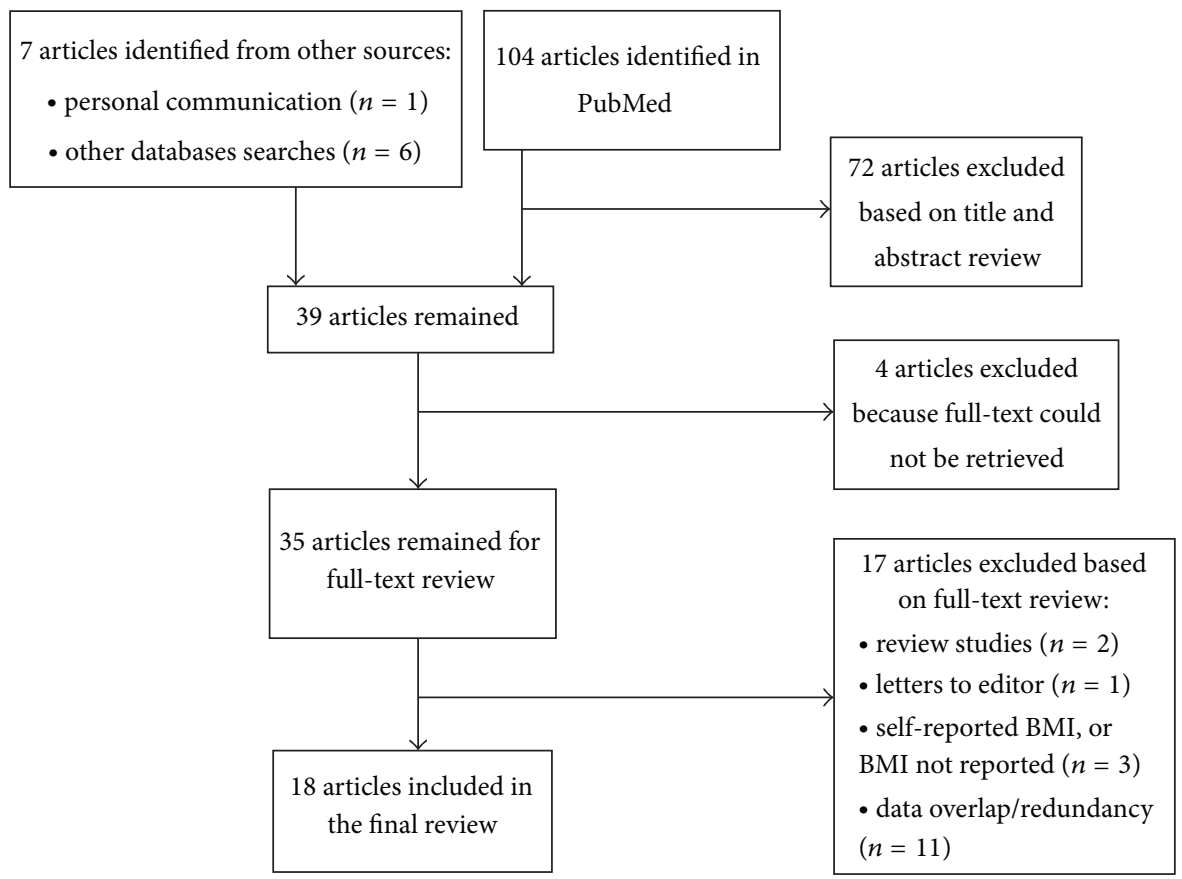

FIgURE 2: Flow chart for articles identification and selection.

studies were subnational based on selected areas of residence (governorates) [18, 34], six were hospital-based [21, 23, 26$29]$, and four were based at a college or university [20, 25, 33] or workplace [31]. A common eligibility criterion across the majority of the studies was Kuwaiti nationality; however, there were three studies which did not differentiate between Kuwaiti and non-Kuwaiti individuals during recruitment [25, 29, 31] and one study that purposely recruited both Arabs and South Asians [23]. With the exception of the KNNS survey that totaled 38,611 subjects over 10 years, the sample size of the remaining studies ranged from 177 to 7,609 subjects. The majority of studies covered a wide age range (on average from
19 through 70 years), but there were also three young adult studies (on average 17 through 25 years) [33], three studies with a shorter age span (19 through 49 years) [21, 27, 30] and one study on the elderly ( $\geq 50$ years) [18]. Overall, the percentage of males in the studies ranged from $36 \%$ to $64 \%$, despite two studies with higher percentage of $85 \%$ and $100 \%$ males [21, 31].

The sampling sources varied from colleges or universities (Public College of Basic Education, Kuwait College of Nursing, Kuwait University), to primary health care clinics, medical centers or private hospitals (Al Rashid Private General Hospital, Abdula Al Salem Health Center, Surra Family 


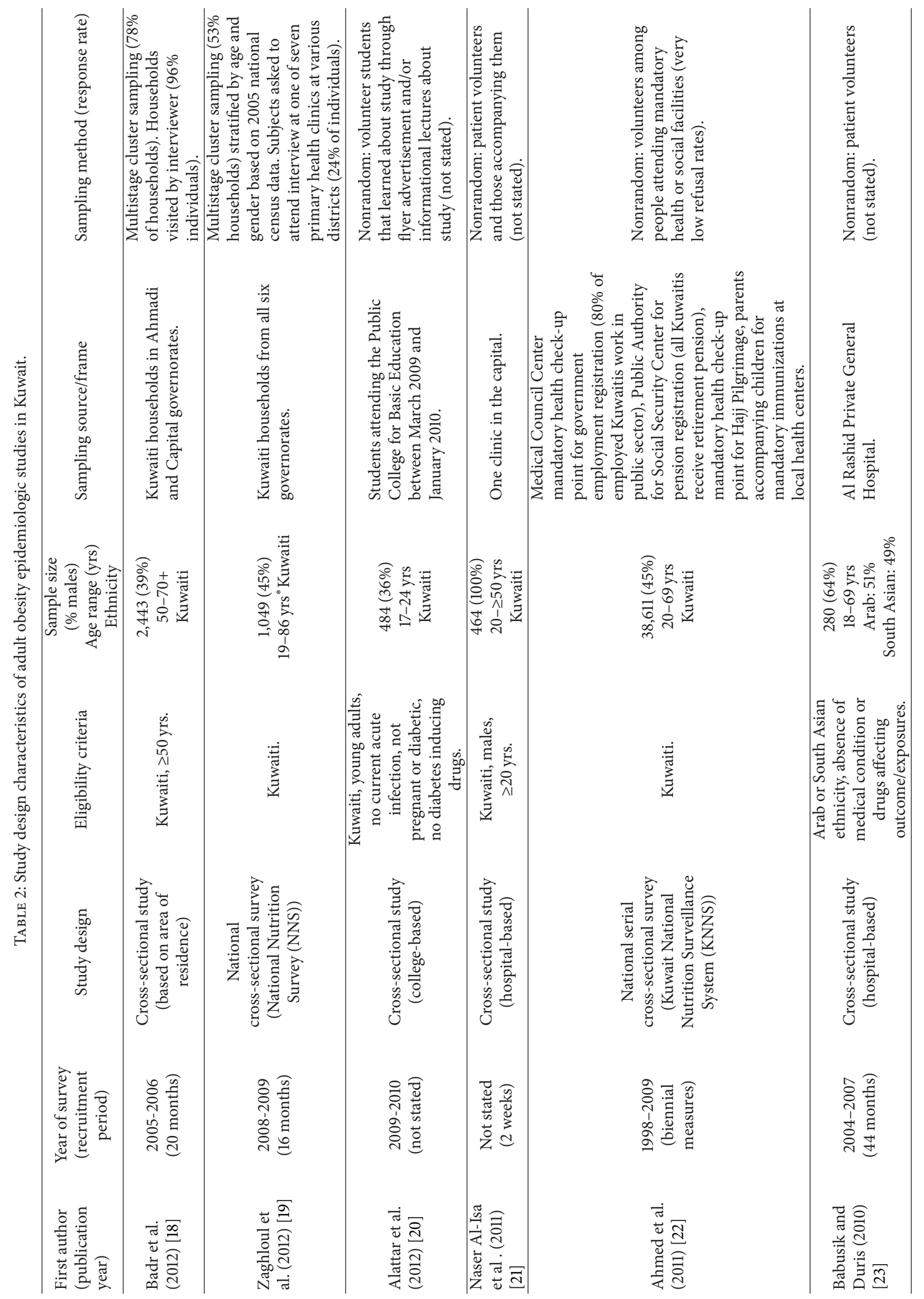




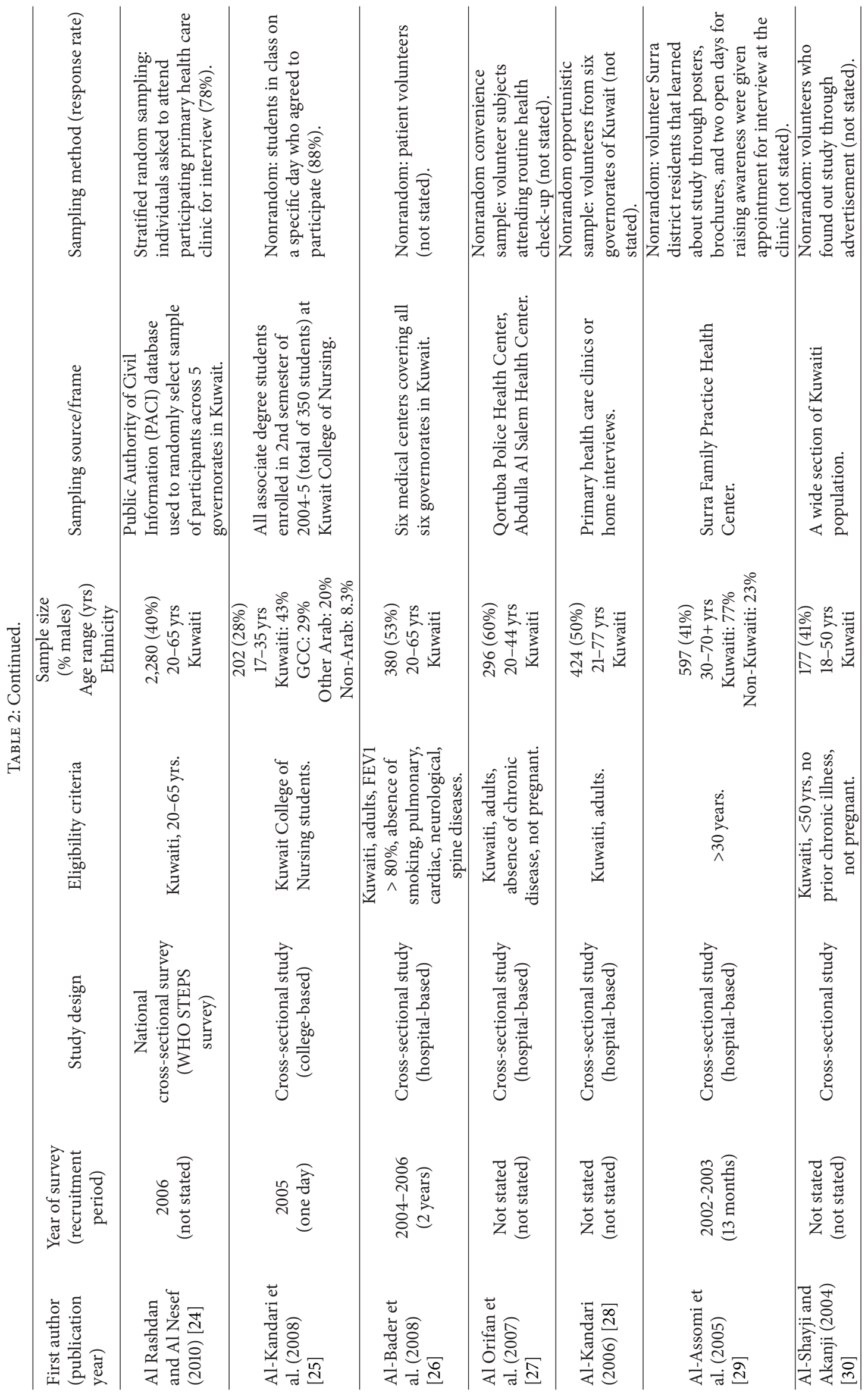




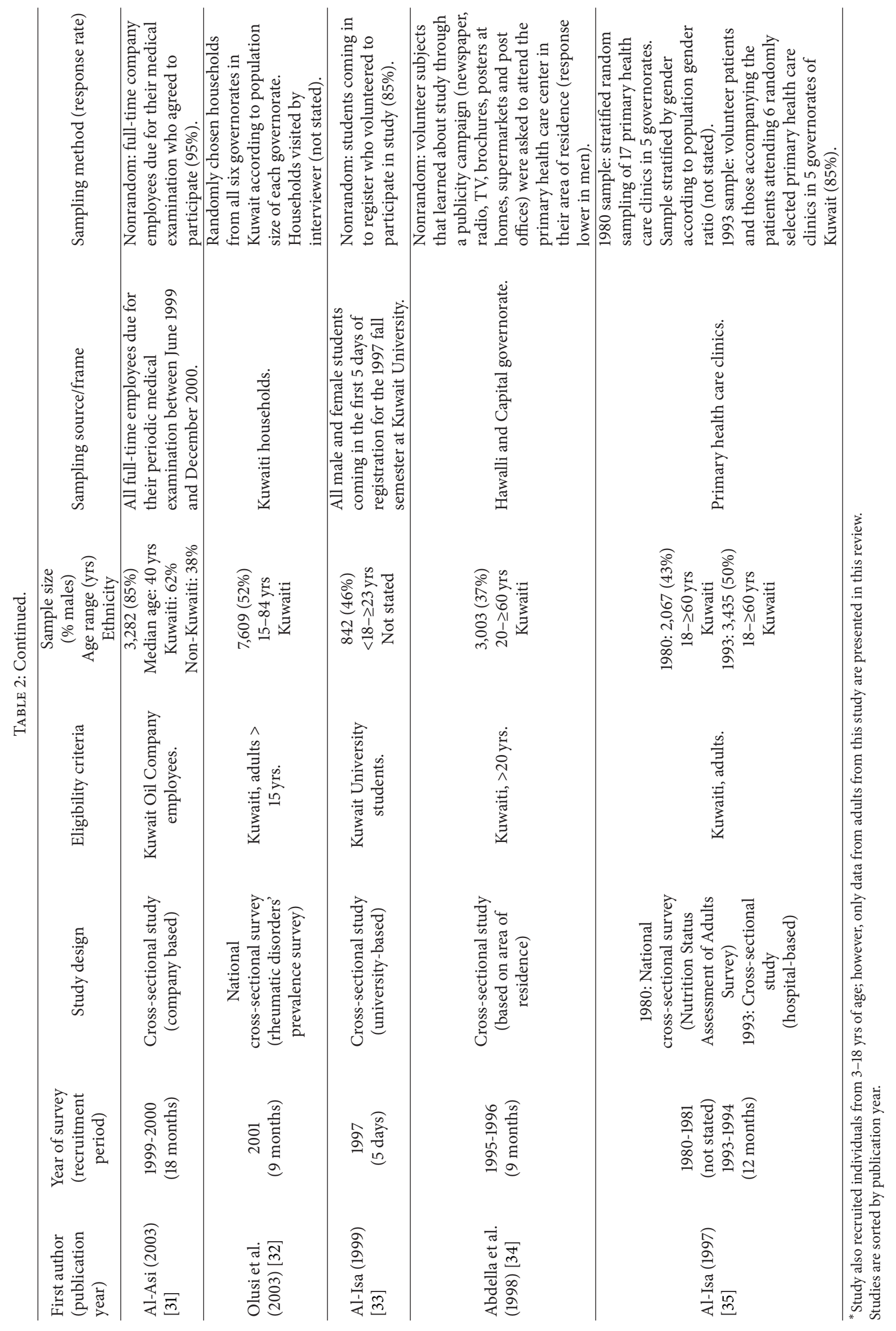


Practice Health Center, Qortuba Police Health Center). On the other hand, the KNNS study used mandatory health check-up points related to the Hajj pilgrimage, children's immunization, or government employment (Medical Council Center), and the social insurance registration center (Public Authority for Social Security Center) to recruit participants. Lastly, databases such as the civil identification database (Public Authority for Civil Information database), households, and selected areas of residence were used as sampling frames in some studies. Only five studies (30\% of total) used random sampling methods (multistage cluster or stratified cluster sampling of households, and stratified random sampling of individuals or primary health care clinics) and all of these were national surveys except one study [18]. The remaining studies, including KNNS, used a nonrandom approach recruiting individuals on a volunteer basis at their chosen sampling source. Three $[18,19,24]$ of the five random sampling studies reported a response rate ranging from $53 \%$ to $78 \%$ for households and $24 \%$ to $96 \%$ for individuals. Only three of the studies with nonrandom sampling reported a response rate that ranged from $85 \%$ to $95 \%$ among volunteer subjects. The remaining 11 out of the 18 studies did not report response rates.

The studies reviewed used face to face interview to collect data and only one study distributed a self-reported questionnaire to participants (Table 3). Out of the 17 studies that used face to face interview 11 studies explicitly stated the use of a questionnaire whereas the remaining 6 did not. The types of data collected in the reviewed studies are outlined for each study in Table 3 and summarized for all studies in Table 4. Some of the studies $(n=7 / 18)$ measured other anthropometric factors in addition to BMI including waist and hip circumference $[19,20,23,24,26,28,30]$ while one of these studies additionally measured triceps and subscapular skinfold thickness [28] (Table S1 see supplementary material available online at http://dx.doi.org/10.1155/2013/378650). All studies used SPSS software to analyze their data. The statistical methods used in 10 out of the 18 studies included multivariate analysis statistical models (linear and/or logistic regression) while the remaining 8 studies used only bivariate analysis statistical tests (Student's $t$-test, chi-square test, $z$ test for proportions, ANOVA F-test, and ANCOVA test). The number of factors included in models to adjust for confounding ranged from zero to seventeen in the different studies. No justification was given in the studies to explain the choice of factors included in the model.

The overall prevalence of obesity (men and women combined) in the studies that reported overall prevalence rates ranged from $9 \%$ to $48 \%$. When college-based studies are not taken into consideration, then the combined prevalence ranges from $20 \%$ to $48 \%$. If only national studies are considered, the prevalence ranges from $24 \%$ to $48 \%$. The majority of studies reported higher prevalence in women than men. Interestingly, in studies with young adult populations (1725 years), the opposite was observed, higher prevalence in men than women. An increase with age was reported and among older age groups ( $>51$ years), prevalence rates were greater than $52 \%$ for both sexes, greater than $39 \%$ for men, and greater than $67 \%$ for women in three national studies [ 19 , $22,24]$. Finally, some studies additionally report a decrease in obesity rates in the very elderly (above 60 or 70 years) $[18,22]$.

Only two studies investigated temporal changes in obesity prevalence rates and reported a significant increase between 1980 and 1993 [35] and between 1998 and 2009 [22] (Table 3). About $70 \%$ of the studies examined obesity as the main outcome, whereas the remaining studies examined obesity as a risk factor for other health outcomes $[20,23,26,27$, 30, 34] (Table S1). Among the risk factors reported to be associated with obesity in these studies were sociodemographic, socio-economic, sociocultural, lifestyle, dietary, and hereditary factors. The specific factors examined and the direction of the association reported are listed for each study in Table 1 and are categorized and summarized for all studies in Table 5. Among the studies that reported associations with health consequences, the health consequences examined and associated with obesity were health conditions such as diabetes, hypertension and osteoarthritis, and physiologic and biochemical outcomes (blood pressure, respiratory, blood lipids, and glucose measures).

Four studies had local and international author affiliations for first and last author [19, 21-23] while the remaining had local affiliations for both first and last author with the most common affiliation being Kuwait University. The journal impact factor for the studies reviewed ranged from 0.12 to 2.48 with the exception of one study with impact factor 7.82 [28] (Table S1).

\section{Discussion}

This is the first review to evaluate obesity epidemiologic studies in Kuwait. In this review, we selected and extracted data from 18 studies according to specified criteria. This data was classified systematically in order to facilitate comparison of studies. Through this work, we were able to identify knowledge gaps and make recommendations for future research directions. This review was restricted to the adult population in Kuwait; however, there have been several informative studies on children. It was beyond the scope of this paper to review the findings on children in order to make possible a comprehensive review on existing adult studies.

The prevalence rates of obesity reported in national studies ranged from $24 \%$ to $48 \%$. The prevalence increased in the last ten years and was significantly higher in women and older adults, indicating that these groups are particularly vulnerable. Not all results from the studies reviewed may be directly comparable because of differences in sampling procedures, age groups, and the year of data collection. Nevertheless, the careful extraction of vital information allows us to identify the factors that may have contributed to variation in results and compare studies which are more similar to each other. Furthermore, the exhaustive literature search and the wide inclusion criteria provide a clear understanding of the current state of obesity epidemiology research in Kuwait including methodology and findings.

The majority of epidemiologic studies reviewed used convenience sampling. Convenience sampling contrary to 


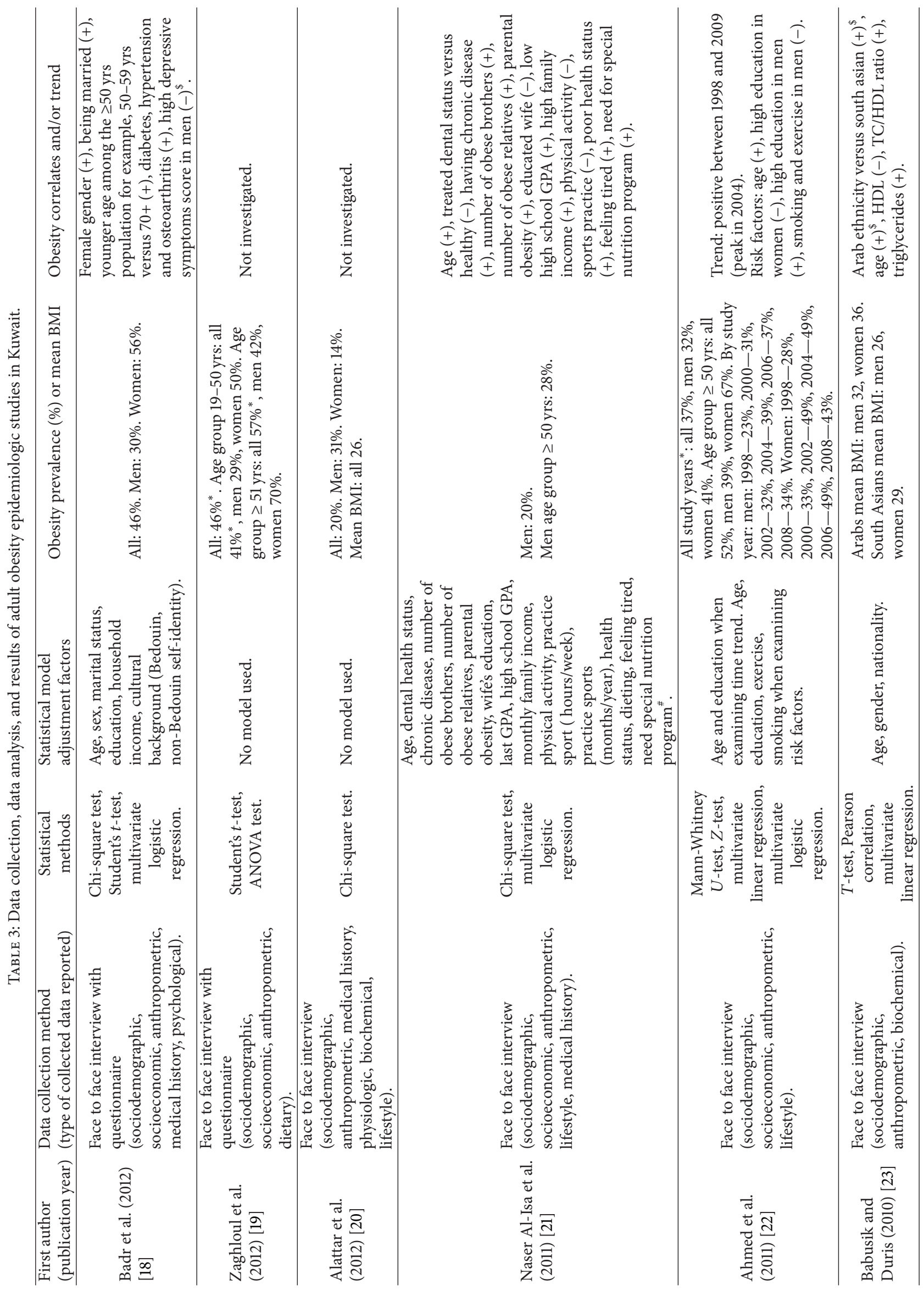




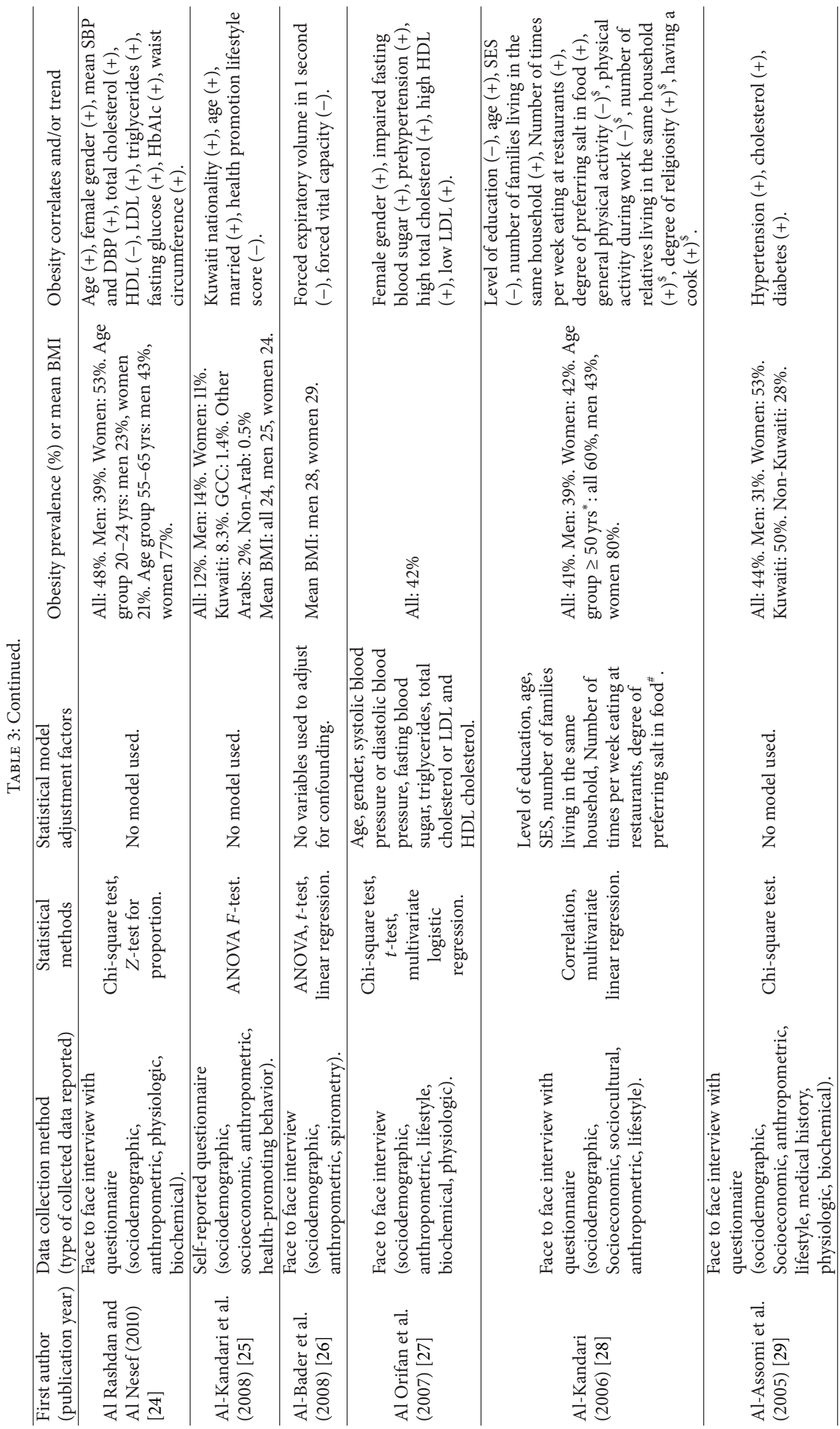




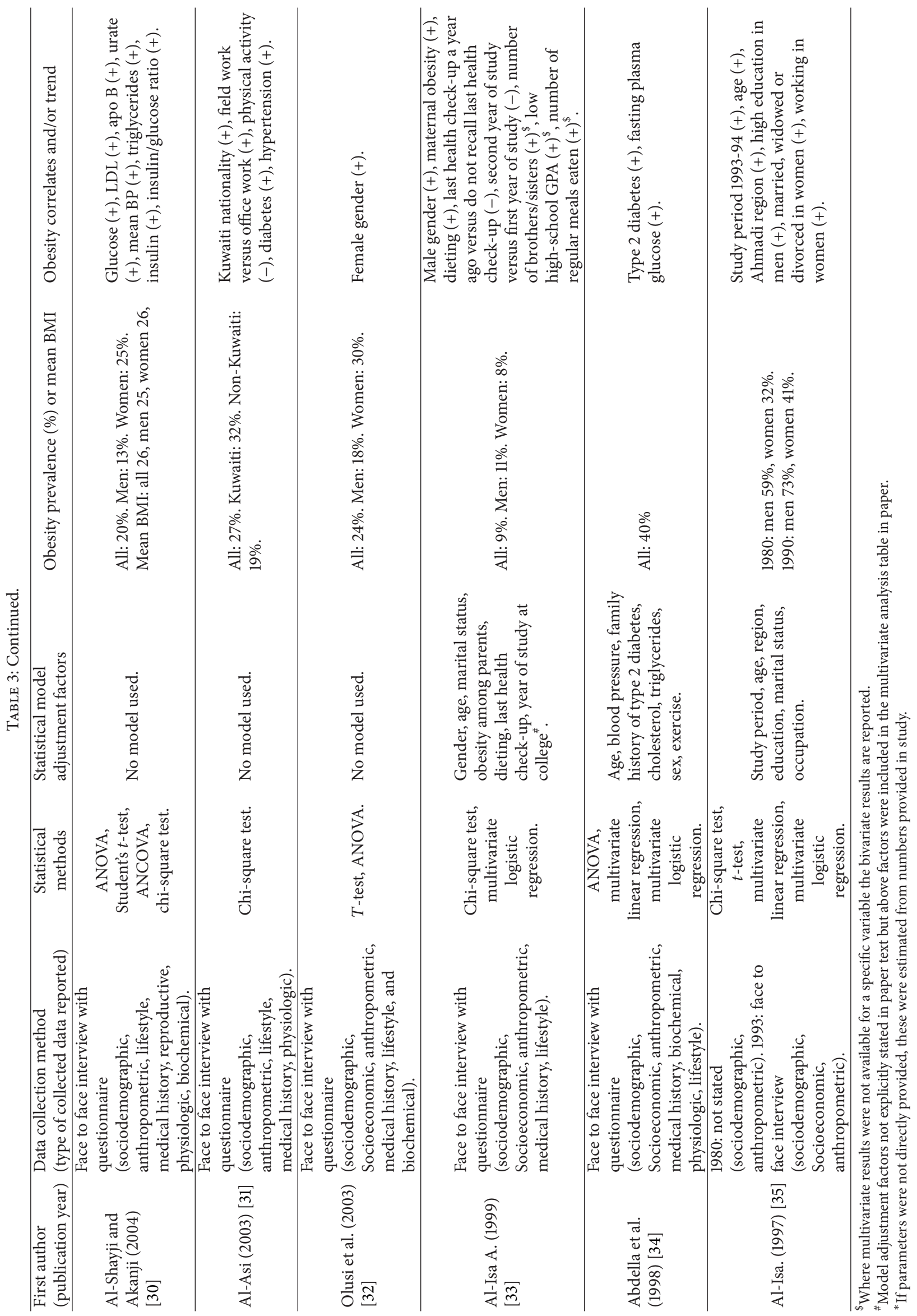


TABLE 4: Types of data collected in reviewed studies.

\begin{tabular}{lc}
\hline Sociodemographic & Dietary \\
Socioeconomic & Hereditary/family history \\
Sociocultural & Medical history \\
Behavioral & Anthropometric \\
Psychological & Physiologic \\
Lifestyle & Biochemical \\
Reproductive & \\
\hline
\end{tabular}

simple or other random sampling methods (stratified, systematic, cluster, or multistage sampling) may introduce bias because the sample may not be representative of the general population. However, there have been five national studies, four of which, used random sampling. The fifth study, KNNS, is the only one that provides detailed information on time trends; however, it did not use random sampling. Possible barriers to using random sampling by the majority of studies in Kuwait may have been requirement of formal access to lists of populations and low response rates among participants due to low levels of awareness, appreciation, and understanding of research. Furthermore, convenience sampling is easier, faster, and inexpensive and Kuwait's small population concentrated in few areas may have encouraged convenience sampling.

In relation to data collection strategies, the crude assessment of factors instead of a thorough and detailed assessment was common in current studies. In future studies, the assessment of different factors in questionnaires can be expanded to include multiple and detailed categories instead of binary categories. For example, information on the duration and intensity of several lifestyle factors including physical activity and smoking may be assessed in the future. The use of other data collection methods, besides face to face interview, such as computer based questionnaire, use of smartphone technologies, telephone interview, or other's can also be considered. In some studies statistical analyses, were limited to simple statistical tests such as chi-square tests and correlations rather than statistical modeling. The collection of detailed factors will also encourage the use of advanced statistical software and analysis that can provide robust findings adjusted for possible confounder's effect.

The results from existing studies on the correlates of obesity provide us with an overview of the risk factors that may be important contributors to obesity in Kuwait. For example, studies report on established factors such as age, gender, education, occupation, income status, physical activity, diet, and smoking but also bring to our attention the importance of sociocultural variables. The role of genetic susceptibility was recognized in existing studies but was only crudely assessed as family history of obesity. All existing studies used the cross-sectional study design and therefore are susceptible to reverse causation bias. Advanced studies, utilizing analytic epidemiologic designs such as prospective cohort, are needed to explore the etiology of "Kuwaiti" obesity in depth. In addition to the above factors, future studies may include investigation of newly emerging players in obesity such as gene-environment interactions, sleep deprivation, and developmental origins [5].

This review highlights the shortcomings of the methodologies used in obesity epidemiology research in Kuwait. Future studies should focus on overcoming these weaknesses by using state-of the-art methods. Priorities must include the design of systematic surveillance surveys to monitor trends and the design of prospective cohort studies with periodic data collections to examine obesity determinants and health consequences [5]. Surveillance monitoring in the United States is conducted by the National Health and Nutrition Examination Survey (NHANES). NHANES consists of crosssectional surveys carried out annually since 1999 to monitor changes in obesity, physical activity, diet, and health outcomes. Around 7,000 individuals across different ages, ethnic backgrounds and income levels are randomly selected and interviewed every year, and collected data are made available to the research community for analysis. In Europe, the European Prospective Investigation into Cancer and Nutrition (EPIC) is an example of a prospective cohort study of half a million individuals in ten European countries followed every three to five years to update lifestyle and disease information. Similarly, in the Nurses' Health Study, 121,700 randomly selected nurses across the US have been followed every two years since 1976 with detailed questionnaires. Information collected from above studies has contributed to knowledge on determinants and health consequences of obesity. For the successful creation of similar studies in Kuwait, future design efforts should consider latest methods while also addressing possible challenges to quantitative research in the region related to systems support and sociocultural influences [55].

Anthropometric measures are the most common way of assessing adiposity. Future studies may incorporate use of new methods such as imaging techniques (dual-energy $\mathrm{X}$ ray absorptiomentry, computed tomography, and magenetic resonance) that measure percentage of body fat and location of fat in tissues [5]. For example, body composition measurements have been extensively used in the Health, Aging and Body Composition (Health $\mathrm{ABC}$ ) study, a prospective study of 3,000 individuals, to investigate the impact of changes in body composition on health of elderly. When focusing on metabolic consequences of obesity, which are highly prevalent in Kuwait, studies must include measures of WC, shown to better predict metabolic outcomes, or combine WC measurements with blood pressure, lipid, and glucose measurements, factors that describe the metabolic syndrome. In this review, less than half of the studies measured WC. Given the current controversy around the importance of fatness versus fitness, future studies must also include assessments of physical activity. Qualitative data from a study conducted in the UAE suggest that girls may be discouraged from exercising once they reach puberty [56]; this has important implications given that physically fit obese individuals may be at a lower risk than unfit obese for developing health outcomes. Finally, macrolevel factors including food subsidies policies in Kuwait and the role of food industry need to be further examined.

Improving the methodology of studies on trends, determinants and consequences of obesity is vital since results 
TABLE 5: Obesity risk factors* ${ }^{*}$ reported in reviewed studies.

\begin{tabular}{|c|c|c|c|c|c|}
\hline Sociodemographic & Socioeconomic & Sociocultural & Lifestyle & Dietary & Hereditary \\
\hline Female gender & $\begin{array}{l}\text { Low high-school } \\
\text { GPA }\end{array}$ & $\begin{array}{c}\text { Number of families } \\
\text { living in same } \\
\text { household }\end{array}$ & $\begin{array}{l}\text { Physical activity } \\
(-)\end{array}$ & $\begin{array}{l}\text { Number of regular meals } \\
\text { eaten daily }\end{array}$ & $\begin{array}{c}\text { Number of obese } \\
\text { brothers }\end{array}$ \\
\hline $\begin{array}{l}\text { Male gender in } \\
\text { college students }\end{array}$ & Education level (-) & $\begin{array}{c}\text { Number of } \\
\text { relatives living in } \\
\text { same household }\end{array}$ & Practice sports $(-)$ & $\begin{array}{c}\text { Number of times per week } \\
\text { eating at restaurants }\end{array}$ & $\begin{array}{c}\text { Number of obese } \\
\text { relatives }\end{array}$ \\
\hline Age & $\begin{array}{l}\text { High education in } \\
\text { men }\end{array}$ & Number of siblings & $\begin{array}{c}\text { Exercise in men } \\
(-)\end{array}$ & $\begin{array}{l}\text { Degree preferring salt in } \\
\text { food }\end{array}$ & Paternal obesity \\
\hline Being married & $\begin{array}{l}\text { High education in } \\
\text { women }(-)\end{array}$ & $\begin{array}{l}\text { Degree of } \\
\text { religiosity }\end{array}$ & $\begin{array}{l}\text { Smoking in men } \\
(-)\end{array}$ & $\begin{array}{l}\text { Need for special nutrition } \\
\text { program }\end{array}$ & Maternal obesity \\
\hline Kuwaiti versus not & Educated wife (-) & & $\begin{array}{c}\text { Treated dental } \\
\text { health status }(-)\end{array}$ & Dieting & $\begin{array}{c}\text { Arab versus } \\
\text { South Asian } \\
\text { ethnicity }\end{array}$ \\
\hline \multirow[t]{5}{*}{$\begin{array}{l}\text { Ahmadi } \\
\text { governorate versus } \\
\text { capital }\end{array}$} & Working women & & $\begin{array}{l}\text { Recent health } \\
\text { check-up (-) }\end{array}$ & & \\
\hline & $\begin{array}{l}\text { Field versus office } \\
\text { work }\end{array}$ & & $\begin{array}{l}\text { Health promoting } \\
\text { lifestyle score }(-)\end{array}$ & & \\
\hline & $\begin{array}{l}\text { High family } \\
\text { income }\end{array}$ & & $\begin{array}{l}\text { High depression } \\
\text { score in men }(-)\end{array}$ & & \\
\hline & $\begin{array}{l}\text { Socioeconomic } \\
\text { status }(-)\end{array}$ & & & & \\
\hline & $\begin{array}{c}\text { Employing } \\
\text { household cook }\end{array}$ & & & & \\
\hline
\end{tabular}

${ }^{*}$ Factors are positively associated with obesity unless inverse association $(-)$ is noted in the parenthesis next to risk factor.

from these studies inform intervention and prevention strategies [5]. The true scale of the problem has not been thoroughly assessed by the existing studies. The primary factors responsible for placing Kuwait in the top 15 countries with the highest obesity prevalence out of 192 countries in the world [9], remain to be elucidated and addressed in prevention campaigns. The effective control and reduction of obesity in Kuwait will require a centralized campaign with policy strategies applied at multiple levels. Malik et al., in their recent review, thoroughly discuss examples of prevention programs implemented in other countries at the government, organization, community, and individual level [7].

In summary, we observed several studies published on the epidemiology of obesity in Kuwait; these were conducted in the last fifteen years and were all cross-sectional. Given the widespread and acknowledged problem of high obesity prevalence rates in Kuwait, we expect to see an increase in the number of studies in coming years. The recent establishment of Dasman Diabetes Institute by the state of Kuwait, a specialized research and treatment center on diabetes and related conditions, further highlights the urgent need to tackle these public health issues in Kuwait. Future research studies may focus on filling the gaps identified through this review and following a comprehensive approach to understanding and resolving the obesity epidemic in Kuwait.

\section{Conflict of Interests}

The authors declared that there is no conflict of interests.

\section{Acknowledgments}

We would like to thank Professor Frank Hu and the reviewers for their valuable feedback and Dr. Hossein Arefanian for his assistance in retrieving necessary bibliography for conducting this review.

\section{References}

[1] M. M. Finucane, G. A. Stevens, M. J. Cowan et al., "National, regional, and global trends in body-mass index since 1980: systematic analysis of health examination surveys and epidemiological studies with 960 country-years and $9 \cdot 1$ million participants," The Lancet, vol. 377, no. 9765, pp. 557-567, 2011.

[2] "Global status report on noncommunicable diseases 2010," Tech. Rep., World Health Organization, Geneva, Switzerland, 2011.

[3] T. Kelly, W. Yang, C.-S. Chen, K. Reynolds, and J. He, "Global burden of obesity in 2005 and projections to 2030," International Journal of Obesity, vol. 32, no. 9, pp. 1431-1437, 2008.

[4] P. L. Remington, R. C. Brwonson, and M. V. Wegner, Chronic Disease Epidemiology and Control, American Public Health Association, Washington, DC, USA, 3rd edition, 2010.

[5] F. Hu, Obesity Epidemiology, Oxford University Press, New York, NY, USA, 2008.

[6] "Global health risks: mortality and burden of disease attributable to selected major risks," Tech. Rep., World Health Organization, Geneva, Switzerland, 2009. 
[7] V. S. Malik, W. C. Willett, and F. B. Hu, "Global obesity: trends, risk factors and policy implications," Nature Reviews Endocrinology, vol. 9, no. 1, pp. 13-27, 2013.

[8] G. W. Guy, A. V. W. Nunn, L. E. Thomas, and J. D. Bell, “Obesity, diabetes and longevity in the gulf: is there a gulf metabolic syndrome?" International Journal of Diabetes Mellitus, vol. 1, no. 1, pp. 43-54, 2009.

[9] WHO, "Global info base international comparisons," 2011, https://apps.who.int/infobase/Comparisons.aspx.

[10] International Diabetes Federation, IDF Diabetes Atlas, International Diabetes Federation, Brussels, Belgium, 5th edition, 2012.

[11] The public authority for civil information statistics, 2012, http://stat.paci.gov.kw/englishreports/.

[12] M. Badran and I. Laher, "Obesity in arabic-speaking countries," Journal of Obesity, vol. 2011, Article ID 686430, 9 pages, 2011.

[13] B. Motlagh, M. O'Donnell, and S. Yusuf, "Prevalence of cardiovascular risk factors in the middle east: a systematic review," European Journal of Cardiovascular Prevention and Rehabilitation, vol. 16, no. 3, pp. 268-280, 2009.

[14] A. O. Musaiger, "Overweight and obesity in eastern mediterranean region: prevalence and possible causes," Journal of Obesity, vol. 2011, Article ID 407237, 17 pages, 2011.

[15] A. O. Musaiger and H. M. Al-Hazzaa, "Prevalence and risk factors associated with nutrition-related noncommunicable diseases in the eastern mediterranean region," International Journal of General Medicine, vol. 5, pp. 199-217, 2012.

[16] S. W. Ng, S. Zaghloul, H. I. Ali, G. Harrison, and B. M. Popkin, "The prevalence and trends of overweight, obesity and nutrition-related non-communicable diseases in the arabian gulf states," Obesity Reviews, vol. 12, no. 1, pp. 1-13, 2011.

[17] L. Alhyas, A. McKay, A. Balasanthiran, and A. Majeed, "Prevalences of overweight, obesity, hyperglycaemia, hypertension and dyslipidaemia in the gulf: systematic review," JRSM Short Reports, vol. 2, no. 7, article 55, 2011.

[18] H. E. Badr, N. M. Shah, and M. A. Shah, "Obesity among Kuwaitis aged 50 years or older: prevalence, correlates and comorbidities," Gerontologist, vol. 53, no. 4, pp. 555-566, 2013.

[19] S. Zaghloul, S. N. Al-Hooti, N. Al-Hamad et al., "Evidence for nutrition transition in Kuwait: over-consumption of macronutrients and obesity," Public Health Nutrition, vol. 16, no. 4, pp. 596-607, 2013.

[20] A. Alattar, H. Al-Majed, T. Almuaili, O. Almutairi, A. Shaghouli, and W. Altorah, "Prevalence of impaired glucose regulation in asymptomatic Kuwaiti young adults," Medical Principles and Practice, vol. 21, no. 1, pp. 51-55, 2011.

[21] A. Naser Al-Isa, J. Campbell, and E. Desapriya, "Factors associated with overweight and obesity among Kuwaiti men," AsiaPacific Journal of Public Health, vol. 25, no. 1, pp. 63-73, 2011.

[22] F. Ahmed, C. Waslien, M. A. Al-Sumaie, and P. Prakash, "Secular trends and risk factors of overweight and obesity among Kuwaiti adults: national nutrition surveillance system data from 1998 to 2009," Public Health Nutrition, vol. 15, no. 11, pp. 2124-2130, 2012.

[23] P. Babusik and I. Duris, "Comparison of obesity and its relationship to some metabolic risk factors of atherosclerosis in arabs and south asians in Kuwait," Medical Principles and Practice, vol. 19, no. 4, pp. 275-280, 2010.

[24] I. Al Rashdan and Y. Al Nesef, "Prevalence of overweight, obesity, and metabolic syndrome among adult Kuwaitis: results from community-based national survey," Angiology, vol. 61, no. 1, pp. 42-48, 2010.
[25] F. Al-Kandari, V. L. Vidal, and D. Thomas, "Health-promoting lifestyle and body mass index among college of nursing students in Kuwait: a correlational study," Nursing and Health Sciences, vol. 10, no. 1, pp. 43-50, 2008.

[26] W. R. Al-Bader, J. Ramadan, A. Nasr-Eldin, and M. BaracNieto, "Pulmonary ventilatory functions and obesity in Kuwait," Medical Principles and Practice, vol. 17, no. 1, pp. 20-26, 2008.

[27] F. H. Al Orifan, H. E. Badr, M. Abdul Sabour Se'adah, K. Elias Khadadah, B. Al Kordi, and A. Abass, "Obesity and cardiovascular risk factor in Kuwaiti adults," Kuwait Medical Journal, vol. 39, pp. 162-166, 2007.

[28] Y. Y. Al-Kandari, "Prevalence of obesity in Kuwait and its relation to sociocultural variables," Obesity Reviews, vol. 7, no. 2, pp. 147-154, 2006.

[29] F. Al-Assomi, S. Al-Kandari, D. Al-Wadaani, and L. Thalib, "Prevalence of cardiovascular risk factors amongst the population of Surra, Kuwait," Journal of the Bahrain Medical Society, vol. 17, no. 3, pp. 161-169, 2005.

[30] I. A. R. Al-Shayji and A. O. Akanji, "Obesity indices and major components of metabolic syndrome in young adult arab subjects," Annals of Nutrition and Metabolism, vol. 48, no. 1, pp. $1-7,2004$.

[31] T. Al-Asi, "Overweight and obesity among Kuwait oil company employees: a cross-sectional study," Occupational Medicine, vol. 53, no. 7, pp. 431-435, 2003.

[32] S. O. Olusi, A. M. Al-Awadi, and M. Abraham, "Baseline population survey data on the prevalence of risk factors for coronary artery disease among Kuwaitis aged 15 years and older," Annals of Saudi Medicine, vol. 23, no. 3-4, pp. 162-166, 2003.

[33] A. N. Al-Isa, "Obesity among Kuwait university students: an explorative study," Journal of The Royal Society for the Promotion of Health, vol. 119, no. 4, pp. 223-227, 1999.

[34] N. Abdella, M. Al Arouj, A. Al Nakhi, A. Al Assoussi, and M. Moussa, "Non-insulin-dependent diabetes in Kuwait: prevalence rates and associated risk factors," Diabetes Research and Clinical Practice, vol. 42, no. 3, pp. 187-196, 1998.

[35] A. N. Al-Isa, "Body mass index and prevalence of obesity changes among Kuwaitis," European Journal of Clinical Nutrition, vol. 51, no. 11, pp. 743-749, 1997.

[36] S. R. Raman, B. Al-Halabi, E. Hamdan, and M. D. Landry, "Prevalence and risk factors associated with self-reported carpal tunnel syndrome (CTS) among office workers in Kuwait," BioMed Central Research Notes, vol. 5, article 289, 2012.

[37] P. Babusik, M. Bilal, and I. Duris, "Nonalcoholic fatty liver disease of two ethnic groups in Kuwait: comparison of prevalence and risk factors," Medical Principles and Practice, vol. 21, no. 1, pp. 56-62, 2011.

[38] S. Al Zenki, H. Al Omirah, S. Al Hooti et al., "High prevalence of metabolic syndrome among Kuwaiti adults-a wake-up call for public health intervention," International Journal of Environmental Research and Public Health, vol. 9, no. 5, pp. 1984-1996, 2012.

[39] H. Al-Shaibani, M. El-Batish, I. Sorkhou et al., "Prevalence of insulin resistance syndrome in a primary health care center in Kuwait," Family Medicine, vol. 36, no. 8, article 540, 2004.

[40] A. N. Al-Isa, "Factors associated with overweight and obesity among Kuwaiti kindergarten female teachers," Nutrition and Health, vol. 18, no. 1, pp. 67-71, 2004.

[41] J. Ramadan and M. Barac-Nieto, "Reported frequency of physical activity, fitness, and fatness in Kuwait," American Journal of Human Biology, vol. 15, no. 4, pp. 514-521, 2003. 
[42] A. N. Al-Isa, "Are Kuwaitis getting fatter?" Nutrition and Health, vol. 17, no. 3, pp. 185-197, 2003.

[43] R. T. Jackson, Z. Al-Mousa, M. Al-Raqua, P. Prakash, and A. N. Muhanna, "Multiple coronary risk factors in healthy older Kuwaiti males," European Journal of Clinical Nutrition, vol. 56, no. 8, pp. 709-714, 2002.

[44] R. T. Jackson, Z. Al-Mousa, M. Al-Raqua, P. Prakash, and A. Muhanna, "Prevalence of coronary risk factors in healthy adult Kuwaitis," International Journal of Food Sciences and Nutrition, vol. 52, no. 4, pp. 301-311, 2001.

[45] A. N. Al-Isa, "Dietary and socio-economic factors associated with obesity among Kuwaiti college men," British Journal of Nutrition, vol. 82, no. 5, pp. 369-374, 1999.

[46] A. N. Al-Isa, "Factors associated with overweight and obesity among Kuwaiti college women," Nutrition and Health, vol. 12, no. 4, pp. 227-233, 1998.

[47] A. N. Al-Isa, "Changes in body mass index (BMI) and prevalence of obesity among Kuwaitis 1980-1994," International Journal of Obesity, vol. 21, no. 12, pp. 1093-1099, 1997.

[48] A. N. Al-Isa, "Changes in body mass index and prevalence of obesity among adult Kuwaiti women attending health clinics," Annals of Saudi Medicine, vol. 17, no. 3, pp. 307-311, 1997.

[49] A. N. Al-Isa, "Temporal changes in body mass index and prevalence of obesity among Kuwaiti men," Annals of Nutrition and Metabolism, vol. 41, no. 5, pp. 307-314, 1997.

[50] A. N. Al-Isa, "Prevalence of obesity among adult Kuwaitis: a cross-sectional study, International Journal of Obesity and Related Metabolic Disorders, vol. 19, no. 6, pp. 431-433, 1995.

[51] F. Al-Awadi and E. K. Amine, "Overweight and obesity in Kuwait," Journal of the Royal Society of Health, vol. 109, no. 5, pp. 175-177, 1989.

[52] M. Alarouj, A. Bennakhi, Y. Alnesef, M. Sharifi, and N. Elkum, "Diabetes and associated cardiovascular risk factors in the state of Kuwait: the first national survey," International Journal of Clinical Practice, vol. 67, pp. 89-96, 2013.

[53] H. T. AlMajed, A. T. AlAttar, A. A. Sadek et al., "Prevalence of dyslipidemia and obesity among college students in Kuwait," Alexandria Journal of Medicine, vol. 47, no. 1, pp. 67-71, 2011.

[54] Y. Al-Nesf, M. Kamel, M. K. El-Shazly et al., "Kuwait STEPS, 2006," Kuwait Ministry of Health, Kuwait, 2006.

[55] T.-C. Aw, T. Zoubeidi, F. Al-Maskari, and I. Blair, "Challenges and strategies for quantitative and qualitative field research in the United Arab Emirates," Asian Pacific Journal of Cancer Prevention, vol. 12, no. 6, pp. 1641-1645, 2011.

[56] G. Berger and A. Peerson, "Giving young Emirati women a voice: participatory action research on physical activity," Health and Place, vol. 15, no. 1, pp. 117-124, 2009. 


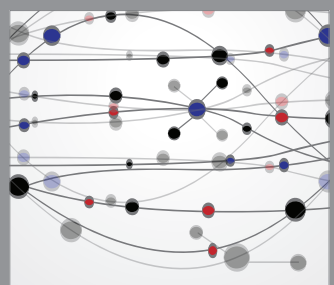

The Scientific World Journal
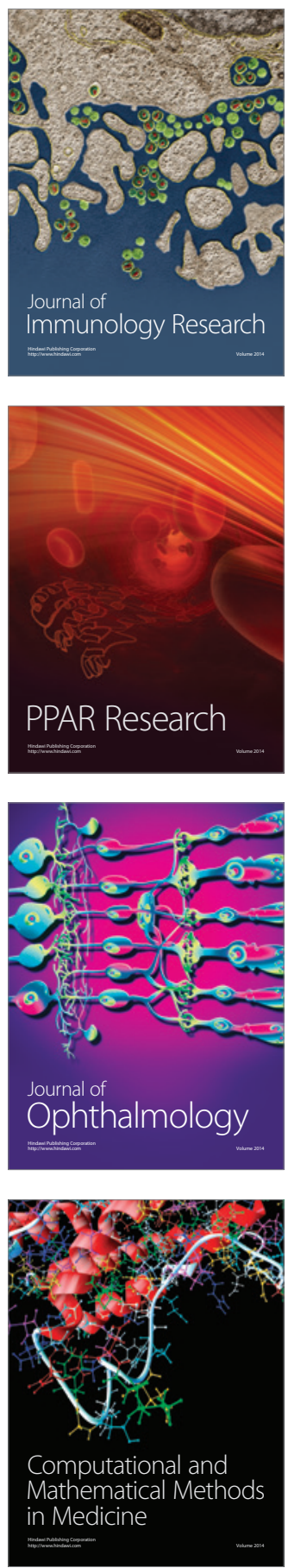

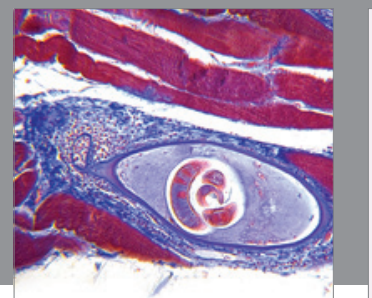

Gastroenterology

Research and Practice
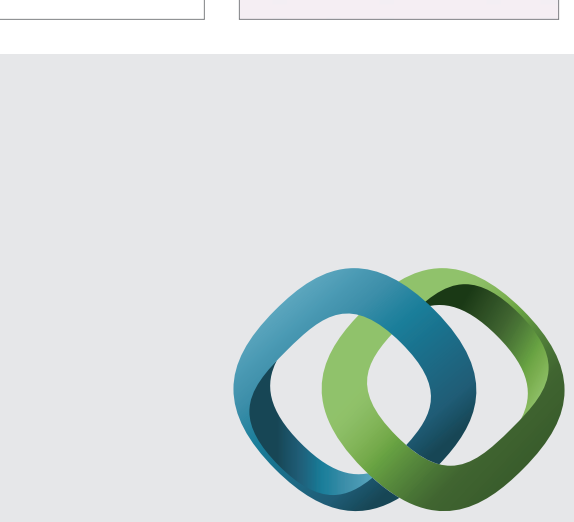

\section{Hindawi}

Submit your manuscripts at

http://www.hindawi.com
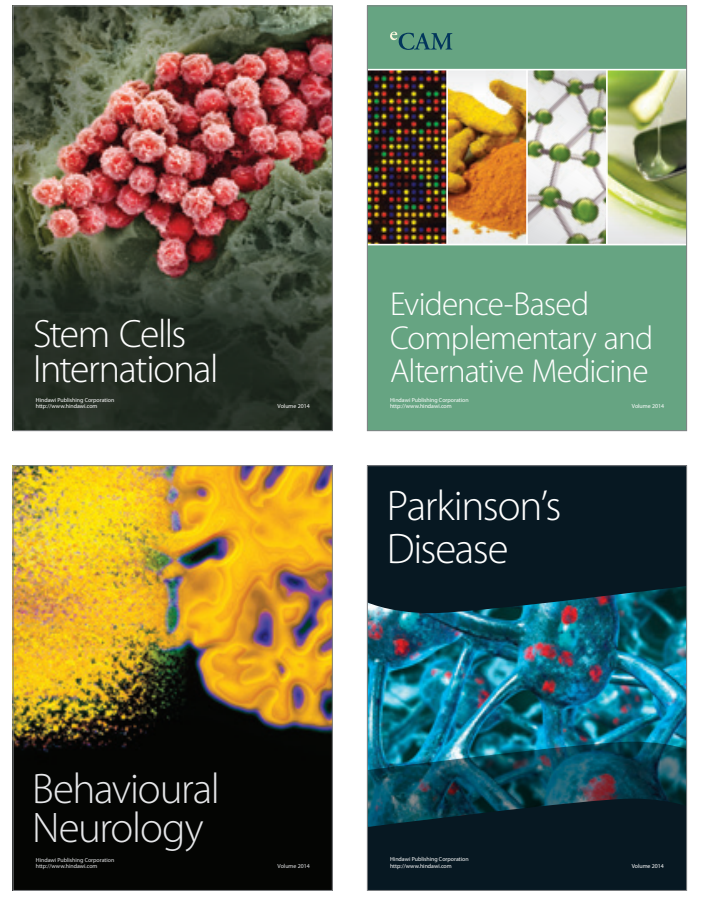
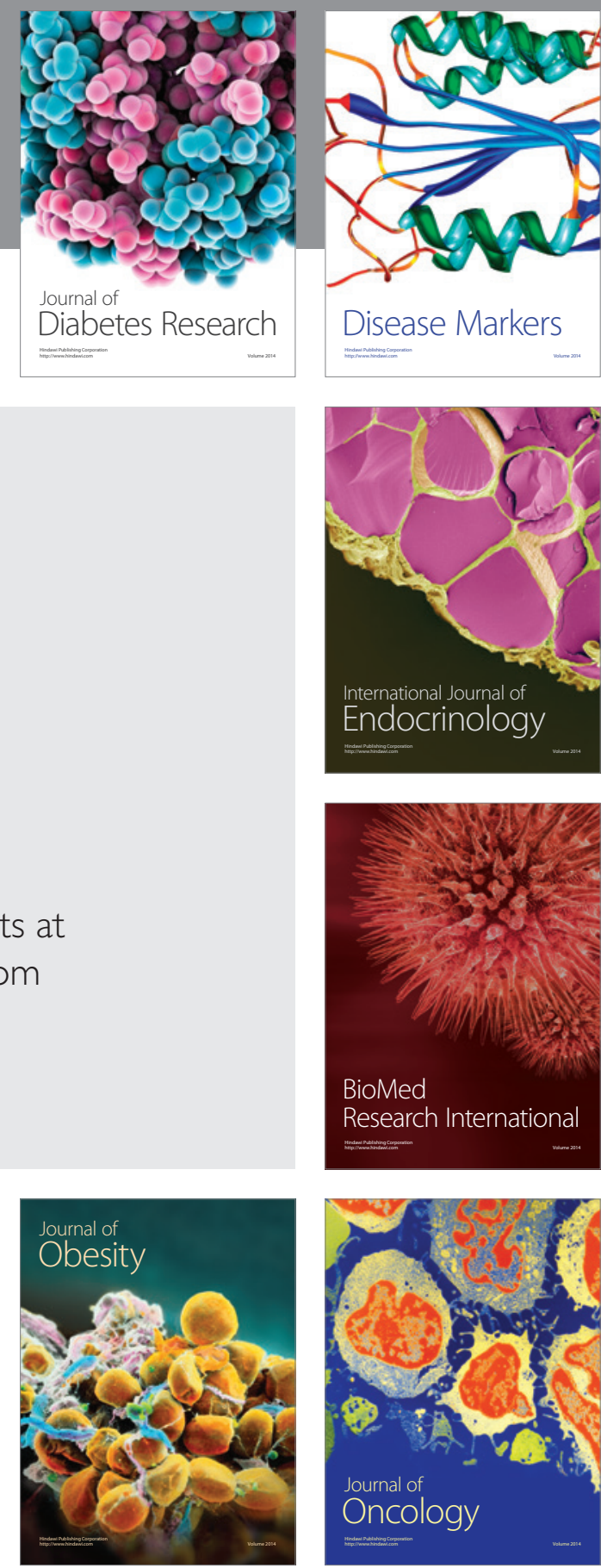

Disease Markers
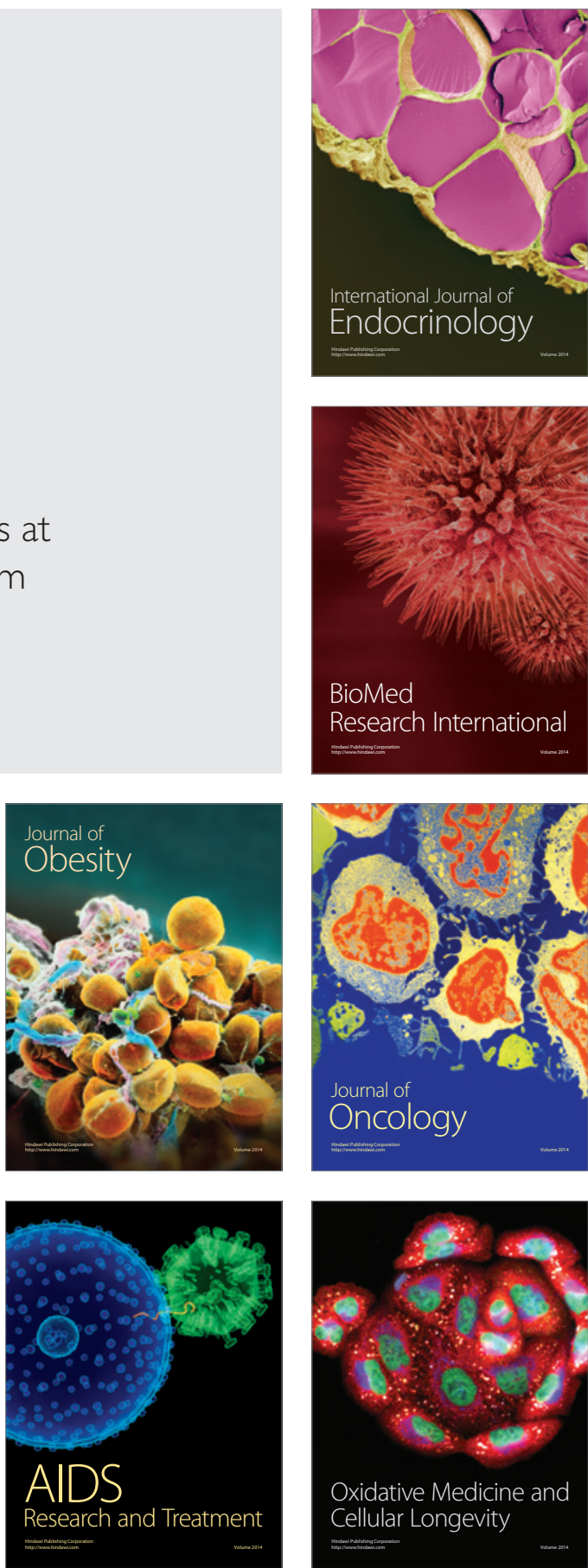